\title{
WITHANOLIDES OF Datura stramonium
}

\author{
R. N. Tursunova, V. A. Maslennikova, \\ and N. K. Abubakirov
}

UDC 547.926

We have studied the withanolide content of the leaves of Datura stramonium L. (jimsonweed datura), family Solanaceae, collected in July, 1975, in the botanical gardens of the Academy of Sciences of the Uzbek SSR in the flowering stage.

The air-dry leaves $(250 \mathrm{~g})$ were extracted with methanol at room temperature. After evaporation of the solvent, the residue was diluted with water (to 0.5 liter) and extracted with $n$-hexane and then with ether. When the hexane fraction was concentrated, it deposited a crystalline mixture of sterols which was difficult to separate and in which, after reprecipitation from ethyl acetate, $\beta$-sitosterol $\left(\mathrm{M}^{+} 414\right)$, stigmasterol (M+412), and campesterol $\left(\mathrm{M}^{+} 400\right)$ were detected by mass spectrometry $[1,2]$.

The ethereal fraction was evaporated, the residue was dissolved in ethanol, the solution was purified by passage through a column of $\mathrm{Al}_{2} \mathrm{O}_{3}$, and the eluate was decolorized with activated carbon. Th is gave a mixture of substances $\left(200 \mathrm{mg}\right.$ ) consisting of three components [TLC on $\mathrm{SiO}_{2}$ with $5 \%$ of gypsum; benzene-ethyl acetate $(1: 1)$; chromogenic agent $\mathrm{SbCl}_{3}$ ]. Preparative chromatography (in the same system) led to the isolation in the crystalline state of $70 \mathrm{mg}$ of pure withanolide (I) with mp $258-260^{\circ} \mathrm{C}, \mathrm{C}_{28} \mathrm{H}_{38} \mathrm{O}_{7}, \mathrm{M}^{+} 486, \lambda \mathrm{C}_{2} \mathrm{H}_{5} \mathrm{OH}$ $225 \mathrm{~nm}(\log \varepsilon 3.95), \nu \mathrm{KBa}_{\max } 3300-3600(\mathrm{OH}), 1730,1695(\mathrm{C}=\mathrm{O}) \mathrm{cm}^{-1}$. The peak of the molecular ion of compound (I) with $\mathrm{m} / \mathrm{e} 486$ and also the peaks of ions with $\mathrm{m} / \mathrm{e} 468(54.5 \%), 450(38.1 \%), 432(12.7 \%), 209(21.8 \%)$, $152(12.7 \%), 125(100 \%)$ show that it was similar to daturalactone - a withanolide from Datura quercifolia HBK [3]. A direct comparison of the substance that we have obtained with an authentic sample of daturalactone kindly supplied by $\mathrm{K}$. Dkhar (Kashmir, India) confirmed their identity.

It must be noted that the mass spectrum of our compound and also that of the sample sent from Kashmir (spectrum taken by ourselves) contained the peak of an ion with $\mathrm{m} / \mathrm{e} 299$ (30\%). It is as yet impossible to explain how a fragmentary ion with such a mass can be formed from daturalactone. It is not excluded that it is the fragment of another withanolide giving a molecular or fragmentary ion with $\mathrm{m} / \mathrm{e} 452$. This compound is obviously present in trace amounts in both samples of daturalactone.

By preparative chromatography we obtained from the ethereal fraction of the extract $6.5 \mathrm{mg}$ of a withanolide which has provisionally been called stramonolide. It had mp $265^{\circ} \mathrm{C}, \mathrm{M}^{+} 484, \mathrm{C}_{28} \mathrm{H}_{36} \mathrm{O}_{7}$.

\section{LITERATURE CITED}

1. G. Kusano, J. Beisler, and Y. Sato, Phytochemistry, 12, 2, 397 (1973).

2. C. S. Tarng and S. J. Stohs, Planta medica, 27, 77 (1975).

3. K. L. Dhar and M. L. Raina, Phytochemistry, 12, 2, 476 (1973).

Institute of the Chemistry of Plant Substances, Academy of Sciences of the Uzbek SSR, Tashkent. Translated from Khimiya Prirodnykh Soedinenii, No. 5, p. 670, September-October, 1976. Original article submitted May 18, 1976.

This material is protected by copyright registered in the name of Plenum Publishing Corporation, 227 West 17th Street, New York, N.Y. 10011. No part of this publication moy be reproduced, stored in a retrieval system, or transmitted, in any form or by any means, electronic, mechanical, photocopying, microfilming, recording or otherwise, without written permission of the publisher. A copy of this article is available from the publisher for $\$ 7.50$. 